\title{
Anther Culture of Potato and Molecular Analysis of Anther-derived Plants as Laboratory Exercises for Plant Breeding Courses
}

\author{
Richard E. Veilleux
}

\begin{abstract}
Summary. Anther culture has been one of the most successful techniques for generating haploid plants over a wide range of species. It is a reasonably simple procedure that can be accomplished successfully without sophisticated laboratory facilities; yet, the plants generated through anther culture can be used to demonstrate the application of many modern methods that have direct applicability to plant breeding. Anthers of diploid potato clones that have been selected for competence in anther culture can be cultured in a simple medium to yield androgenic embryos after 5 weeks. Plant regeneration requires an additional 3 to 4 weeks. Regenerated plants should be large enough 2 weeks after transfer to basal medium for ploidy determination by any of three methods depending on available facilities: chromosome counts in root tips; chloroplast counts in stomatal guard cells; or flow cytometry of nuclei released from in vitro plantlets. DN A can be extracted from anther-derived plantlets using a rapid extraction procedure to demonstrate segregation of PCR (polymerase chain reaction)-based markers such as RAPD (randomly amplified polymorphic DNA), RAM Ps (randomly amplified microsatellite polymorphisms), or microsatellites. M icrosatellite markers that were heterozygous in the anther donor can be used to verify haploidy in anther-derived plants. If an anther culture laboratory is scheduled early in a semester, such molecular analysis can be planned for late in the same semester.
\end{abstract}

nther culture has been envisioned as a route to the rapid and efficient development of homozygous lines for hybrid breeding. Though first reported in 1964 by Guha and M aheshwari for the jimsonweed, D atura stramonium L., the technique was quickly adapted to commercially important crops and can now be applied to many major crops (Khush and Virmani, 1996). Anther-derived cultivars have been released for canola, Brassica napus L. (Stringam et al., 1998), asparagus, A sparagus officianalis L. (Corriols et al., 1990) and wheat, Triticum aestivum L. em Thell. (de Buyser et al., 1987), among others (K hush and Virmani, 1996; Veilleux, 1994). Application of haploidization techniques to self-pollinated crops has generally been more successful because of the lack of inbreeding depression in homozygous lines. A major difference of haploidization compared to self-pollination to derive homozygous lines of cross-pollinated crops is the lack of selection for fertility among doubled haploid regenerants.

D epartment of H orticulture, Virginia Polytechnic Institute \& State U niversity, Blacksburg, Virginia 24061.

The cost of publishing this paper was defrayed in part by the payment of page charges. U nder postal regulations, this paper therefore must be hereby marked advertisement solely to indicate this fact. 
Inbred lines are per force more likely to be fertile because the infertile ones are lost during the inbreeding process. Therefore, in cross-pollinated crops, one can expect a more diverse array of homozygotesby haploidization followed by chromosome doubling compared to inbreeding, but not all regenerants may be useful. In addition, haploidization to derivehomozygoteswill bypassbreeding barrierssuch asself-incompatibility or incongruency.

$\mathrm{H}$ aploidization of cultivated potato (Solanum tu berosum L.), a tetraploid $(2 n=4 x=48)$, results in the recovery of largely dihaploid lines ( $2 n$ $=2 x=24$ ) that still embody considerable heterozygosity. The term dihaploid has been used to describe haploid plants derived from a tetraploid. It should not be confused with doubled haploid, used to describe the product of chromosome doubling after haploidization. Reduction of dihaploid potato to the monoploid level $(2 n=1 x=12)$ has resulted in the recovery of weak unpromising plants. H owever, Solanum phureja Juz. \& Buk. is a diploid cultivated potato that has been used extensively in potato breeding as a source of disease resistance and other valuable traits. A diverse population developed from accessions of both S. phureja and itsclose relative, S. stenotomum, was adapted to long photoperiod and temperate conditions (H aynes, 1972). This population comprises a diverse array of germplasm that has been selected for heat tolerance, $2 \mathrm{n}$ pollen, anther culture competence and other traits. Although $\mathrm{S}$. phureja is considered by some to be unpromising because of irregular tuber shape, deep eyes, or poor storage capability, thepopulation issufficiently diverse that any of these characteristics can be subdued through selection of more agronomically acceptable traits or breeding at the diploid level with S. tuber osum dihaploids. Because of the dominance of anther culture competence, hybrids between clones competent to form embryos from cultured anthers and other diploid germplasm generally respond to anther culture (Singsit and Veilleux, 1988). The following protocol describes how $\mathrm{S}$. phureja can be used as laboratory material to demonstrate the application of anther culture to a cross-pollinated crop followed by the use of microsatellite markers to examine anther-derived plants.

\section{Handling of the plant material}

Solanum phureja grows and flowers best under cool greenhouse conditions, $25^{\circ} \mathrm{C}$ day/ $15^{\circ} \mathrm{C}$ night $\left(77^{\circ} \mathrm{F} /\right.$ $\left.59^{\circ} \mathrm{F}\right)$, long photoperiod $(16 \mathrm{~h})$ and high light intensity provided by high pressure sodium vapor lamps. The author can supply clones that respond well to anther culture. In Virginia, there are two greenhouse seasons that induce adequate flowering to be able to conduct anther culture- planting in August for $\mathrm{O}$ ctober to $\mathrm{N}$ ovember experiments and planting in J anuary for $M$ arch to April experiments. Supplemental lighting should be provided starting around 15 Sept. for the August planting and as soon as the plants have emerged for the January planting. (It can be discontinued after 1 A pr. for thespring planting.) Theplants will flower best given adequate space for root development, e.g., using 7.6$L$ (2-gal) nursery potsor growing them directly in ground beds containing 1 sand : 2 soilless mix (Sunshine, Fisons $\mathrm{H}$ orticulture Inc., Vancouver, BC, Canada or Pro-M ix BX, Premier Brands, Inc., Red H ill, Pa.). Theplants require weekly fertilization with a water soluble fertilizer such as Peter's Fertilizer Products(W.R. Grace\& C o., Fogelsville, $\mathrm{Pa}$.) containing $20 \mathrm{~N}-8.4$ $\mathrm{P}-14.9 \mathrm{~K}$. A systemic insecticide such as $\mathrm{M}$ arathon (Olympic $\mathrm{H}$ orticultural Products, $M$ ainland, $P$ a.) should be applied when planting the tubers to control thrips and whiteflies. Some type of support, such asflower support netting (product 761020; H ummert, International, Earth City, Mo.) or stakes, is necessary. O nce flowering has started, $\approx 10$ to 20 buds per plant per day can be collected three times per week.

\section{Anther culture procedure}

Flower buds with microspores at the uninucleate stage (anthers 2.5 to $3.5 \mathrm{~mm}$ in length) are most responsive to anther culture and can be picked and placed on paper towels moistened with distilled water in plastic sandwich bags. The buds are then refrigerated at $4{ }^{\circ} \mathrm{C}$ for $3 \mathrm{~d}$ in the dark. The buds (in batches of $\approx 30$ ) are then surface-sterilized in $70 \%$ ethanol for $30 \mathrm{~s}$ and disinfected in 100\%commercial bleach (5.25\% sodium hypochlorite) plus Tween 20 for $5 \mathrm{~min}$. Then, they are rinsed twice in sterile distilled water.
Anthers ( $\approx 30$ per flask) are aseptically removed and placed in $125 \mathrm{~mL}$ D elong culture flasks (Bellco Glass Co., Vineland, N .J .) containing $15 \mathrm{~mL}$ autoclaved 1/ 2 strength Linsmaier and Skoog (1965) medium with $2.5 \mathrm{mg} \cdot \mathrm{L}^{-1} \mathrm{BA}+$ $0.1 \mathrm{mg} \cdot \mathrm{L}^{-1}$ IAA + $2.5 \mathrm{~g} \cdot \mathrm{L}^{-1}$ activated charcoal. Each flask should be closed with a M agenta two-way cap ( $M$ agenta Plastics, Chicago, III.) and sealed with parafilm. Flasks are then shaken on a rotary shaker, set at 125 to $150 \mathrm{rpm}$, at room temperature $\left(\approx 25^{\circ} \mathrm{C}\right)$. A fter 5 to 6 weeks, the embryos can beharvested by pouring the contents of the flask through an autoclaved tea strainer, rinsing with sterile water and inverting the strainer over a Petri plate. The embryos can be separated from the anthers and counted under a dissecting microscope. To demonstrate experimental design and analysis of a tissue culture experiment, treatments can be applied during anther culture. The comparison of five treatments using a randomized anther technique where each anther per bud is distributed to one of five treatments until all flaskscontain 30 anthers hasbeen found to be most convenient statistically (Snider and V eilleux, 1994). Completion of three replications per day on several days to reach 9 to 12 replications will allow rigorous statistical analysis for day and treatment effects using SAS GLM procedure (SAS, 1985) or any other statistical package that handles ANOVA. Although any number of treatments can be envisioned, those that examine the effects of different sugars or activated charcoal at various concentrations tend to give the most dramatic results.

\section{Regeneration of anther- derived embryos}

The embryos from anther culture should be transferred to regeneration medium: $3.2 \mathrm{~g} \cdot \mathrm{L}^{-1} \mathrm{G}$ amborg'sB5 salts (Gamborg et al., 1968) with minimal organic compounds (Sigma G 5893, St. Louis, M o.), $50 \mathrm{mg} \cdot \mathrm{L}^{-1} \mathrm{C} \mathrm{HH} \mathrm{PO}_{4}$, $748 \mathrm{mg} \cdot \mathrm{L}^{-1} \mathrm{CaCl}_{2}, 250 \mathrm{mg} \cdot \mathrm{L}^{4^{\prime}}$ $\mathrm{NH}_{4} \mathrm{NO}_{3}, 10 \mathrm{~g} \cdot \mathrm{L}^{-1}$ sucrose, $6 \mathrm{~g} \cdot \mathrm{L}^{-1}$ agarose (Sigma Type IIIA, No. A 9793), $0.1 \mathrm{mg} \cdot \mathrm{L}^{-1}$ gibberellic acid (filter-sterilized), pH 5.6, and incubated at $20^{\circ} \mathrm{C}$ under high intensity light $\left(175 \mu \mathrm{mol} \cdot \mathrm{s}^{-1} \cdot \mathrm{m}^{-2}\right)$. At 3-week intervals, the regenerated embryoscan be counted and transferred to $25 \times$ $150 \mathrm{~mm}$ culture tubes containing 20 $\mathrm{mL}$ M S basal media ( $M$ urashige and 
Skoog, 1962) supplemented with vitamins, $100 \mathrm{mg}^{\cdot \mathrm{L}^{-1}}$ myo-inositol, 100 $\mathrm{mg} \cdot \mathrm{L}^{-1}$ casein hydrolysate, $3 \%$ sucrose and $0.7 \%$ Gibco Phytagar (Life T echnologies, I nc., G aithersburg, $M$ d.), pH 5.8 , while the unregenerated embryos may be transferred to fresh regeneration medium. U nregenerated embryos are generally discarded 3 weeks after the last transfer. Although additional transfers may yield more regenerants, the regeneration frequency generally declines after three transfers. The regenerants are kept in a growth room at $\approx 20^{\circ} \mathrm{C}$ under a 16 -h photoperiod and $50 \mu \mathrm{mol} \cdot \mathrm{s}^{-1} \cdot \mathrm{m}^{-2}$ provided by cool whitefluorescent lamps. Thefrequency of regenerated plantsfrom androgenic embryos (regeneration frequency) can then be calculated.

\section{Ploidy analysis}

The ploidy of plantlets derived from the regenerated androgenic embryos may be estimated by flow cytometric examination of propidium iodide stained nuclei from in vitroleaf and stem tissue (O wen et al., 1988). If flow cytometry facilities are unavailable, the number of chloroplasts per pair of guard cells may be counted under a fluorescence microscope to estimate ploidy (Singsit and Veilleux, 1991). This procedure involves removing epidermal peels from in vivo or in vitro leaves with a fine forceps, painting them with 5\%FD A stain prepared in acetone diluted 1:20 with water just before use. The stain can be applied with an artist's brush and the green-stained chloroplasts observed under a fluorescence microscope (250¥) equipped with a fluorescein isothiocyanate (FITC) filter combination. The number of chloroplasts should be counted for a minimum of 10 pairs of guard cells. M ean chloroplasts per guard cell pair ranges from 9 for monoploids to 15 for diploids and 20 for tetraploids. Alternatively, chromosomes can be counted in root tips from in vitro plantletsaccording to the methods described by Fukui and $\mathrm{N}$ akayama (1996). H owever the small size of potato chromosomes makes chromosome counts challenging.

\section{Simple sequence repeat (SSR) and RAPD analysis}

Once sufficient anther-derived plantshave been obtained, they can be analyzed with molecular markers to verify ploidy or examine segregation patterns. Total genomic D N A can be extracted from in vitro plant material according to D oyle and D oyle (1987) as modified by Veilleux et al. (1995). M icrosatellite primers ( 20 to 24 base pairs; $60{ }^{\circ} \mathrm{C}$ melting temperature) flanking SSR containing potato sequences from the European M olecuIar Biology Laboratory (EMBL)/ G enbank databasehavebeen designed with the software Primer version 0.5 (Chani, 1997). The reaction mix (20 $\mu \mathrm{L})$ contains: $1 \times$ assay buffer $(50 \mathrm{~mm}$ $\mathrm{KCl}, 10 \mathrm{~mm}$ Tris-H Cl (pH 9), 1\% Triton X-100), $3 \mathrm{~mm} \mathrm{M} \mathrm{gCl}, 160 \mu \mathrm{m}$ of each of the dNTPs, 1.5 units Taq polymerase(Promega, $M$ adison, Wis.), $0.1 \mu \mathrm{m}$ of each primer, and $50 \mathrm{ng}$ genomic D N A overlaid with a drop of mineral oil (Yu et al., 1994). A PCR protocol consisting of 40 cycles at 94 ${ }^{\circ} \mathrm{C}$ for $1 \mathrm{~min}, 55^{\circ} \mathrm{C}$ for $2 \mathrm{~min}, 72^{\circ} \mathrm{C}$ for $1.5 \mathrm{~min}$, followed by $5 \mathrm{~min}$ at 72 ${ }^{\circ} \mathrm{C}$ was used. Amplified fragments are separated in 3\%M etaphor agarosegels (FM C Bioproducts, Rockland, M e.) in TBE buffer for 4 to $8 \mathrm{~h}$ at 90 to 100 V. Chi-square tests ( $1 \mathrm{df}$ ) may be performed for each primer pair to check for skewness from the expected 1:1 ratio for each marker that is polymorphic in the anther donor. Polymorphism is determined by heterozygosity for SSR length fragments. A polymorphic anther donor has two alleles that differ by the number of repeats of the SSR motif. These different alleles have differing mobilities in the gel with shorter fragments migrating further. M onoploids have only a single allele per locus and hence are expected to express only one band. An example of the type of result expected is given in Fig. 1. Because microsatel lite markers are codominant, the presence of more than a singleallele at any locus in an anther-derived plant would indicate that it is not monoploid. We have identified plants as mono ploid by flow cytometry but needed to discard them subsequently because microsatellite analysis revealed heterozygosity (lane 7 in Fig. 1).

We have doubled the chromosomenumber of anther-derived monoploids of S. phureja to generate homozygouslines( $M$ 'R ibu and Veilleux, 1992). These doubled monoploids haveexhibited femalefertility and could be crossed with heterozygous diploid potato selections. They represent the only currently available homozygous potato lines that can be used in genetic studies due to the breeding barriers that prevent derivation of homozygotesthrough self-pollination and the severe inbreeding depression that cultivated potato suffers.

For a laboratory exercise, the instructor should have flowering plants of $S$. phureja available at the beginning of a semester, i.e., they should be planted $\approx 6$ weeks before the start of classes. The anther cultures can be done during the first 2 weeks. Each

Fig. 1. Amplification of the actc simple sequence repeat (SSR)containing region of the waxy locus of potato by primers designed from GenB ank accession X52417 in an anther-derived potato family. L ane 1 is the 100 base pair ladder. L ane 2 is the negative control without DNA. $L$ anes 3 and 4 are the parents of the anther donor. L ane 5 is the heterozygous anther donor ( $S$. phureja clone C P2). L anes 6 through 27 are 22 anther-derived plants of C P2. All are homozygous except for L ane 7 which represents a plant that had been erroneously classified as a monoploid. The locus exhibits distortion among the monoploids with the faster migrating (shorter SSR) fragment overrepresented. H eterozygotes exhibit three bands because the uppermost band represents heteroduplex formation (adapted from C hani, 1997).

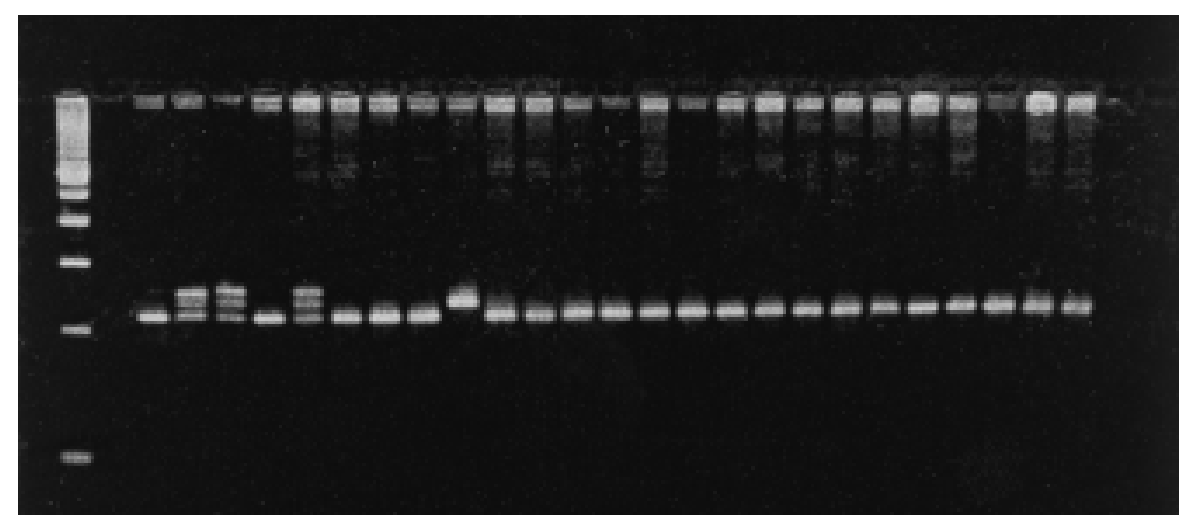


student should culture $\approx 100$ to 200 anthers over two laboratory sessions; therefore, at least two plants per student should be grown to providesufficient flowers. Flower budscan be collected every $2 d$ and refrigerated until use. Embryos can be transferred twice, once 5 to 6 weeks after anther culture and again 3 weeks later. O n transfer, any regenerated embryos can be placed on M S basal medium so that regenerated plants are ready 10 weeks after the start of the semester. Ploidy analysis can then be done nondestructively using either in vitro leaflets for chloroplast counts or shoot tips for flow cytometry. By weeks 13 to 14 , D N A can be extracted and marker analysis completed at the end of the semester. These exercisesare moresuitablefor an upper division undergraduate or graduate class in plant breeding and genetics. Wehave doneall of these exercises in a graduate plant breeding class at Virginia Tech with the assistance of a graduate teaching assistant to prepare media or reagents. The anther culture without additional analyses can be educational and does not require sophisticated equipment. A routinely equipped tissue culture lab would have most of the required equipment, perhaps with the exception of an orbital shaker to accommodate $125 \mathrm{~mL}$ flasks. Advantages of using potato for anther culture are the ease of dissection of flower buds and the prolific embryo production of selected clones. These clones also flower abundantly under proper environmental conditions and the regeneration of embryoshasbeen greater than $80 \%$ for some clones.

\section{Literature cited}

Chani, E. 1997. Molecular marker analysis of a segregating monoploid potato family. PhD diss., Va. Polytech. Inst. State U niv., B lacksburg.

Corriols, L., C. Dorj, and C. Rameau. 1990. Commercial release in $\mathrm{F}$ rance of $A$ ndreas, the first asparagus all-male $F$ hybrid. Proc. 7th Intl. Asparagus Symp., 19-23 June, Ferrara, I taly. Acta H ort. 271:249-252.

de Buyser, J., Y. H enry, P. Lonnet, R. H ertzog, and A. H espel. 1987. 'Florin': A doubled haploid wheat variety developed by the anther culture method. Plant Breeding 98:53-56.

D oyle, J.J. and J.L. Doyle. 1987. A rapid DNA isolation procedure for small quantities of fresh leaf tissue. Phytochemistry Bul. 19:11-15.

Fukui, K. and S. Nakayama (eds.). 1996. Plant chromosomes: Laboratory methods. CRC Press, Boca Raton, Fla.

Gamborg, O., R. Miller, and K. Ojima. 1968. $\mathrm{N}$ utrient requirements of suspension culture of soybean root cells. Expt. C ell. Res. 50:151-158.

Guha, S. and S.C. Maheshwari. 1964. In vitro production of embryos from anthers of Datura.
N ature 204:497.

H aynes, F.L. 1972. The use of cultivated Solanum species in potato breeding, p. 100-110. In: E.R. French (ed.). Prospects for the potato in the developing world: An international symposium on key problems and potentials for greater use of the potato in the developing world, I ntl. Potato Center, Lima, Peru 17-29 July.

Khush, G.S. and S.S. Virmani. 1996. H aploids in plant breeding, p. 11-33. In: S.M. Jain, S.K. Sopory, and R.E. Veilleux (eds.) In vitro haploid production in higher plants. vol. 1. Fundamental aspects and methods. Kluwer Academic Publishers, D ordrecht, The N etherlands.

L insmaier, E. and F. Skoog. 1965. O rganic growth factor requirements of tobacco tissue cultures. Physiol. Plant. 18:200-127.

M 'Ribu, H.K. and R.E. Veilleux. 1992. Fertility of doubled monoploids of Solanum phureja. Amer. Potato J. 69:447-459.

M urashige, T. and F. Skoog. 1962. A revised medium for rapid growth and bioassays with tobacco tissue cultures. Physiol. Plant. 15:472-497.

O wen, H.R., R.E. Veilleux, F.L. H aynes, and K.G. H aynes. 1988. Variability for critical photoperiod for tuberization and tuber yield among monoploid, anther-derived genotypes of potato. J. Amer. Soc. H ort. Sci. 113:755-759.

SAS. 1985. SAS user's guide: Statistics. version 5. SAS Inst. Inc., Cary, N.C.

Singsit, C. and R.E. Veilleux. 1988. Intra- and interspecific transmission of androgenetic competencein diploid potato species. E uphytica43:105112.

Singsit, C. and R.E. Veilleux. 1991. A comparative study of chloroplast density in guard cells of in vitro versus in vivo leaves of anther-derived potato plants. H ortScience 26:592-594.

Snider, K.T. and R.E. Veilleux. 1994. Factors affecting variability in anther culture and in conversion of androgenic embryos of Solanum phureja. Plant Cell Tissue O rgan Cult. 36:345-354.

Stringam, G.R., M.R. Thiagarajah, V.K. Bansal, and D.F. D egenhardt. 1998. Practical breeding applications of microspore culture and doubled haploidy in Brassica napus. L., p. 111. In: Plant biotechnology and in vitro biology in the 21st century. IX Intl. Congr. Plant Tissue and Cell Cult., Jerusalem, I srael, 14-19 June (abstr.).

Veilleux, R.E. 1994. Development of new cultivars via anther culture. H ortScience 29:12381241.

Veilleux, R.E., L.Y. Shen, and M .M. Paz. 1995. Analysis of the genetic composition of antherderived potato by randomly amplified polymorphic D N A and simple sequence repeats. Genome 38:1153-1162.

Yu, Y.G., M .A. Saghai M aroof, G.R. Buss, P.J . M aughan, and S.A. Tolin. 1994. RFLP and microsatellite mapping of a gene for soybean mosaic virus resistance. Phytopathology 84:60-64. 